\title{
Respiratory change and mental task gradient
}

JOHN K. ADAMOWICZ, DAVID GIBSON AND DAVID KAUFMAN THE UNIVERSITY OF CALGARY

The proposed connection between mental task difficulty levels and heart rate change was examined using a respiration measure and pretested intensities of mental task demand and white noise for $27 \mathrm{Ss}$. Similarity of direction and magnitude of results between studies based on cardiovascular measures and the present respiration findings indicate that conclusions can be generalized physiologically. Interpretations were offered with respect to the formulations of Lacey and of Malmo.

Relationships between a number of psychophysiological indices and ideational activity have been reported as early as 1895 (Mentz) and elaborated by Skaggs (1930) and by Darrow (1929). Recent investigations have centered on the examination of cardiovascular changes in relation to behavioral outputs (Lacey et al, 1962; Obrist, 1963; Gibson \& Hall, 1966; Costello \& Hall, 1967). Dependence on any single autonomic criterion of behavior change is, however, problematical in view of evidence that autonomic system measures display both paradoxical and idiosyncratic subject variability (Sternbach, 1966; Lacey et al, 1962; Malmo, 1965; Ax, 1953, Schnore, 1959).

Gibson and Hall observed that the energy demands of mental tasks are related to heart rate such that weak task demands required greater cardiac bolstering than did strong task demands. The present study will reassess the posited connection between cardiovascular (CVS) change and mental work gradient, and examine the directional characteristics of this relationship, employing respiration rate as the activation index. Respiration indices are espectally suited to the present study because: (1) resplration is known to influence change in other physiological variables (Sternbach, 1966); (2) heart rate and respiratory changes are closely related under a variety of stimulus conditions (Westcott \& Huttenlocher, 1961); and (3) respiratory measures rank with cardiovascular measures as comparatively reliable and consistent indices of arousal (Schnore, 1959).

\section{Subjects}

The Ss were 27 students attending the University of Calgary (CA ranged from 18 to 25 years).

\section{Apparatus}

The apparatus was a Grass Model 7 polygraph. Respiration rate was recorded using chest bellows and a Grass PT-5A volumetric low pressure transducer. White noise, which was transmitted through Sharpe HA 10 stereo earphones and wired so that both of the $S^{\prime} s$ ears received the same signal, was produced by a Maico noise generator.

\section{Procedure}

Difficulty of mental task was arranged in three stages of task intensity: no task, easy task, and dif- ficult task. The Ss were required to invent grammatically correct sentences of five words, each word in the sentence to begin with $C$ for the easy task condition and $Q$ for the difficult task condition. A pilot study using two samples of $33 \mathrm{Ss}$ was conducted to establish relative difficulty of the task letters employed. All Ss completed all tasks during the experimental session.

Intensity of white nolse was arranged in three stages: no noise, distractive noise ( $85 \mathrm{~dB})$, and noxdous noise $(100 \mathrm{~dB})$. A pilot study was run to determine the intensity of distractive noise (1.e., clearly palpable but not noxious) and the noxious noise condition. The method of limits was used with 25 Ss.

The Ss were randomly assigned to the nine experimental conditions. Stereophonic earphones were worn by all $\mathrm{Ss}$ in a noise controlled environment. The room was darkened to decrease visual input. The bellows tube was attached around the abdomen or chest area of each S. Ss reclined comfortably on an adjustable bed, and relaxation was encouraged for $10 \mathrm{~min}$ during which a basal rate was established. Number of breaths per min was used in the analysis of variance (McNemar, 1962).

\section{Results and Discussion}

Mental task gradients and respiratory change were significantly related, irrespective of background conditions ( $F=10.1, \mathrm{df}=2 / 18, p<.01)$. Figure 1 shows that an easy task is associated with the greatest respiratory increase from the base line, whereas the most difficult task exacts an increase approximately medial between the no task and easy task conditions. Noise levels and task levels are, however, not significantly interrelated under respiratory system monitoring ( $F=.96, d f=4 / 18$ ). Respiratory measures do not vary significantly across three auditory condi-

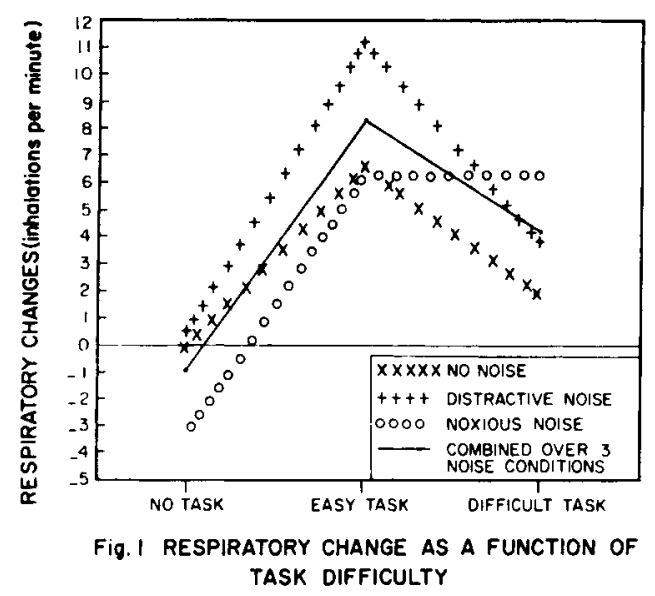


tions $(F=.91, d f=2 / 18)$. These findings support the earlier results of Gibson and Hall and Costello and Hall with respect to the connection of task gradient and CVS change, but not with respect to the association of second source auditory gradient, task levels, and CVS change.

One mechanism underlying a Lacey type problem solving situation has been postulated by Malmo (1965). He proposed that physiological changes occur in order to compensate the cortex so that an even attentional level is maintained by it. EEG evidence (Malmo, 1965) showed that cortical activity remained relatively constant during the sequence when skeletal-motor and cardio-respiratory levels displayed progressive rise. Adjusting tonic background is perhaps part of the physiological activity required to sustain an even or at least a task appropriate attentional level from beginning to end of task or from task to task. Gibson \& Hall (1966) had suggested that greater cardiac shielding will occur when the energy demands of a task are not sufficiently intense to evoke adequate attention levels. A Lacey "silent elaboration" mental task which was not especially demanding of Ss might more easily lead to dissipation of task orientation by external or internal stimulus conditions irrelevant to the performance of the mental task.

Similarity of findings between the CVS and respiration measures indicate that previous CVS based conclusions can be generalized physiologically and that cardiovascular measures apparently provide a relatively sensitive and stable monitor of cognitive and arousal phenomena. Further research might manipulate autonomic system activation levels in relation to stimulus input-output conditions.

\section{References}

AX, A. F. The physiological differentiation between fear and anger in humans. Psychosom. Med., 1953, 433-442.

COSTELLO, C. G., \& HALL, M. K. Heart rates during performance of a mental task under noise conditions. Psychon. Sci., 1967, in press.

DARROW, C. W. Differences in the physiological reactions to sensory and ideational stimuli. Psychol. Bull, 1929, 26, 185-201.

GIBSON, D., \& HALL, M. K. Cardiovascular change and mental task gradient. Psychon. Sci., 1966, 6, 245-246.

LACEY, J. I., KAGAN, J., LACEY, B. C., \& MOSS, H. A. The visceral level: Situational determinants and behavioural correlates of autonomic response patterns. In P. Knapp (Ed.), Expressions of the emotions in man. New York: International Universities Press, 1962.

MALMO, R. B. Physiological gradients and behavior. Psychol. Bull. 1965 , 64, 225-234.

McNEMAR, Q. Psychological statistics. New York: John Wiley and Sons, Inc., 1962.

MENTZ, P. Die Wirkung akustischer Sinnesceize auf Puls und Atmung. Phil Stud., 1895, 11, 61-131.

OBRIST, P. A. Cardiovascular differentiation of sensory stimuli. Psychosom. Med., 1963, 5 (25), 450-459.

SCHNORE, M. M. Individual patterns of physiological activity as a function of task differences and degree of arousal. J. exp. Psychol, 1959, $58,117-128$.

SKAGGS, E. B. Studies in attention and emotion. J. comp. physiol. Psychol, 1930, 10, 375-419.

STERNBACH, R. A. Principles of psychophysiology. New York: Academic Press, 1966.

WESTCOTT, M. R., \& HUTTENLOCHER, J. Cardiac conditioning: The effects and implications of controlled and uncontrolled respiration. J. exp. Psychol., 1961, 61, 353-359.

Note

1. Supported by N.R.C. (Canada) Grant No. APA-220 to the second author. 